\title{
A experiência do filosofar e o filosofar como experiência
}

\author{
Juliana Merçon (1)
}

Com o texto que aqui começa a se delinear, proponho-me a discutir, a partir de dois conceitos de experiência, diferentes questões que concernem à filosofia, o seu ensino e a sua ligação com o gênero feminino. Problematizaremos o que na constituição da experiência do filosofar o vincula ao reconhecimento dos saberes, aos métodos de ensino e a identidades que paralisam seu próprio movimento. Suspeitamos que essas vinculações dificultem a emergência do filosofar como experiência, como aquilo através do qual modificamos a nossa relação com os saberes, com os poderes e com o que somos. A tentativa de identificar os elementos que nos distanciam do nosso próprio pensar se configura como um esforço para cultivar com a nossa própria vida uma relação artística, que nos crie e recrie, com intensidade, sentido e beleza.

\section{Experiência e pensamento:}

\section{Constituição e transformação de si}

O termo experiência tem diversas faces. Muitas vezes falamos, por exemplo, que fulano é experiente, que tem muita experiência em um assunto ou atividade. Com isso costumamos denotar um certo acúmulo de saber, domínio de conhecimentos ou habilidades aperfeiçoadas através da repetição dos atos. A experiência apareceria aqui como algo cumulativo, quase quantificável e que permitiria o progresso rumo a um fim muitas vezes antecipável. Este sentido do termo experiência parece-me pouco interessante para pensar a filosofia. Isto porque o pensamento e o filosofar talvez não estejam tão relacionados ao acúmulo de saberes, à repetição dos atos ou a qualquer tipo de progresso.

Gostaria de sugerir outros dois sentidos para o termo experiência, os quais nos ajudarão a pensar a própria filosofia. Estes foram extraídos da última parte da obra de Michel Foucault. A primeira definição que exploraremos convida-nos a pensar a experiência como "a correlação, numa cultura, entre campos de saber, tipos de normatividade e formas de subjetividade" (Foucault, 1984, p. 10). Os campos de saber que constituem a experiência referem-se ao conjunto de discursos e práticas que legitimam algumas proposições como verdadeiras e outras como falsas. Em nossa sociedade, esses discursos e práticas estão centrados na ciência e nas instituições que a produzem. Eles são divulgados através dos aparelhos de educação e/ou de informação, são intensamente consumidos pela população, e incitam a produção econômica e o poder político (Foucault, 1988, p. 13). Por tipos de normatividades, podemos entender os diferentes discursos e práticas que determinam formas corretas de agir. Estes estabelecem o campo favorável para as nossas ações, assim como as sanções para aqueles que não seguirem as normas. Os tipos de normatividades que constituem a experiência dizem respeito, portanto, aos sistemas de poder que regulam as nossas práticas. $\mathrm{O}$ terceiro eixo que participa 
do que chamamos experiência é o que Foucault chamou de formas de subjetividade. Estas se referem às maneiras através das quais nós podemos e devemos nos reconhecer como sujeitos. Lembramos que para este mesmo autor há dois sentidos sempre conectados ao ser sujeito: "sujeito a alguém pelo controle e pela dependência, e preso à sua própria identidade por uma consciência ou autoconhecimento, isto é, pela forma como este sujeito é levado a dizer 'eu sou'. Ambos sugerem uma forma de poder que subjuga e torna sujeito a" (Foucault, 1995, p. 235).

Apoiando-nos neste sentido dado à experiência, podemos dizer que a experiência do filosofar é constituída 1. por discursos e práticas que estabelecem sua verdade (a verdade sobre o que é a filosofia e a verdade de seus conteúdos ou saberes), 2. por tipos de normatividades que prescrevem uma ou mais formas corretas de exercê-la e 3. pelas maneiras através das quais os indivíduos se reconhecem como sujeitos filósofos. Filosofar seria assim uma experiência sempre submetida a regimes de verdade, a relações de poder e a modos de subjetivação atuantes em um determinado tempo e cultura.

Mas a experiência tem também para Foucault um outro sentido. Ela é aquilo que nos faz ser diferentes do que somos, ela permite "arrancar o sujeito de si mesmo, fazer com que ele não seja mais ele mesmo, ou que seja levado à sua aniquilação ou à sua dissolução; é uma tentativa de des-subjetivação" (Foucault, 1994, p. 43). A experiência é aquilo através do qual nos tornamos outro, e o filosofar, neste sentido, seria uma "experiência modificadora de si no pensamento" (Foucault, 1984, p. 13). A experiência do filosofar poderia assim nos levar ao filosofar como experiência.

Se a experiência é, por um lado, o que nos constitui como sujeitos, nos fazendo dizer 'eu sou' e estabelecer um certo tipo de relação cognoscitiva e moral com o nosso eu, ela é, por outro lado e ao mesmo tempo, aquilo que nos permite desprender desse eu e desse 'ser' um eu. É o que nos possibilita des-ser, é o que nos coloca em 'devir'- outro, outra, outros. A experiência que nos torna o que somos seria também condição para que nos tornemos algo diferente do que vínhamos sendo (Nascimento, no prelo). A experiência do filosofar estaria assim sempre submetida a verdades, poderes e modos de subjetivação, mas também pode se tornar o espaço no qual irromperá o filosofar como experiência, ou seja, o pensamento, sempre imprevisível, irrepetível e intransferível, que nos liberta de algumas verdades, poderes e formas de ser.

Pensar o 'eu' como o que se constitui nesta trama de saberes, relações de poder e modos de subjetivação, e também como aquilo que é transformado pela experiência me leva a refletir sobre o meu próprio eu (que talvez não seja assim tão próprio) e a minha relação com a filosofia. Embora seja sempre constituída socialmente, a experiência é também algo que só pode ser vivido de forma singular. No âmbito da cultura, partilhamos a linguagem, verdades, códigos morais, $e$, portanto, formas de pensar, agir e ser. No entanto, a posição concreta que ocupo no entrecruzamento desses aspectos me diferencia dos outros indivíduos, fazendo com que haja uma dimensão de sentido não partilhada, só por mim 
experienciada. Quando digo "eu sou professora de filosofia", estou vinculando ao meu ser, ao que em parte me define, uma das atividades que desenvolvo (a de professora), o atributo de gênero (sou professora e não professor), e o que qualifica minha atividade (filosofia). Refletir sobre as maneiras através das quais a nossa cultura promove esta experiência talvez possa gerar espaços para uma possível transformação na forma como individualmente nos posicionamos frente ao ensino da filosofia. Proponho-me então a discutir brevemente três dimensões gerais que constituem a experiência de professora de filosofia, a saber: a filosofia, seu ensino $e$ o feminino. Parto da suspeita de que algumas formas de viver a filosofia, seu ensino e o gênero feminino dificultam o filosofar como experiência, ou seja, a transformação de si através do pensamento. Lanço-me também na aposta de que talvez essa reflexão afete o que supomos ser íntimo ou muito nosso na forma como praticamos a filosofia.

O saber e a filosofia:

o reconhecimento como obstáculo para o pensar

"Nossa veneração diante do que já foi feito, por mais válido e belo que seja, nos petrifica, nos estabiliza e nos impede de tomar contato com a força que está acima, e que podemos chamar de energia pensante, de força vital, ou qualquer outra coisa" Antonin Artaud, 1983, p. 71

"(...) o próprio do novo, isto é, a diferença, é provocar no pensamento forças que não são as da recognição, potências de um modelo totalmente distinto, numa terra incógnita nunca reconhecida, nem reconhecível" Gilles Deleuze, 1988, p. 225

Parece-me que em nossa cultura a filosofia possui pelo menos dois retratos, que podem ser vistos como opostos ou até mesmo complementares, sendo ambos veiculados com grande força. Por um lado, a ela não se atribui valor algum. A filosofia é a atividade dos ociosos e vagabundos, dos que não estão em sintonia com as demandas da atualidade, com as regras do mercado. Ela teria sido há tempos superada pela ciência. É irrelevante, é inútil em nosso mundo de informações rápidas, regido pela economia e pelo marketing. Este retrato da filosofia talvez assombre um pouco os que se dedicam a ela e que se vêem em diferentes ocasiões compelidos a prover explicações sobre sua vida profissional ou modo de ser. No entanto, será o segundo retrato o que aqui nos interessará mais, pois ingenuamente irei supor que nós, aqui presentes, por acreditarmos na importância do vínculo entre educação e filosofia, não vemos nessa primeira imagem da filosofia algo que nos afaste dela, mas talvez justamente o que nos faça lutar por seu espaço, pela beleza de seu canto em um mundo de tantos ruídos.

Comentaremos mais o seu segundo retrato. Este nos leva muitas vezes a crer que a filosofia é uma atividade dificílima, quase impossível, e, portanto, praticada por um 
grupo seleto de pessoas extremamente privilegiadas. Essas pessoas teriam sido premiadas geneticamente $e$ nascido com um intelecto superior, ou adquirido habilidades de raciocínio e conhecimentos através de sua passagem por contextos muito especiais (famílias eruditas, escolas tradicionais, universidades reconhecidas). Assim como usualmente se veicula a imagem do cientista maluco em seu laboratório com tubos de ensaio, teríamos também o estereótipo do filósofo como um erudito de gestos refinados, cercado por livros com conteúdos indecifráveis para a maioria. Como fundo desta imagem, teríamos diversos pressupostos, sendo um deles o de que a filosofia é para poucos porque é preciso possuir muitos saberes para filosofar. Deleuze (1998, p.21) diria, no entanto, que a filosofia com sua história e conjunto de saberes a serem reconhecidos é justamente o que nos impede de filosofar:

A história da filosofia sempre foi um agente de poder na filosofia, e mesmo no pensamento. Ela desempenhou o papel de repressor: como você quer pensar sem ter lido Platão, Descartes, Kant e Heidegger, e o livro de fulano ou siclano sobre eles? Uma formidável escola de intimidação que fabrica especialistas do pensamento, mas que também faz com que aqueles que ficam fora se ajustem ainda mais a essa especialidade da qual zombam. Uma imagem do pensamento, chamada filosofia, constituiu-se historicamente e impede perfeitamente as pessoas de pensarem.

O saber filosófico que nos fazem crer ser condição para o pensar, este saber interminável e sempre além de nosso alcance, opera assim como um obstáculo constante que paralisa o nosso pensamento e, portanto, o próprio filosofar. Se as pessoas que procuram filosofar são estudantes, professores não universitários, se vêm de outras áreas, ou, mais gravemente, se são crianças, este mecanismo de controle e inibição do pensar filosófico se torna ainda mais marcante. A institucionalização do pensamento age, sutil e eficientemente, legitimando algumas vozes e desautorizando outras, protegendo espaços, reduzindo ameaças.

Seria tolo imaginar, no entanto, que para nos opormos a esta estratégia de intimidação do pensamento bastaria desconsiderar a história da filosofia. Penso que, embora ela não seja uma condição necessária para o filosofar, ela pode, dependendo de como nos relacionamos com ela, servir como uma imensa inspiração e potencializar o nosso pensamento. Talvez possamos não apenas reconhecer, mas também nos encontrar com os saberes e, pensando com ou a partir deles, desconstruir o que já sabíamos. Talvez possamos aprender com a filosofia a sermos mais inquietos e até mesmo mais corajosos para enfrentarmos inclusive o que nos diz que é preciso saber tudo para depois ousarmos pensar.

O pensar, portanto, talvez tenha menos a ver com os saberes que acumulamos, talvez diga menos respeito ao reconhecimento, à confirmação e à legitimação do que já sabemos. Isto porque o pensar não se conforma ao que já é, ele move-se em direção ao não sabido. Ele pulsa entre o saber e o não saber. $\mathrm{O}$ saber não engloba o pensamento, embora possa se tornar o problema que o coloca em movimento. $\mathrm{O}$ saber pode passar a ser o ponto de partida do pensar até que ele chegue a algum lugar, até que este lugar seja tornado saber e assim se cesse o 
pensar. Em poucas palavras, onde há acomodação, reconhecimento e legitimação do que já sabemos há pouco ou nenhum pensamento, há pouca ou nenhuma filosofia.

O pensamento como inquietude diante dos saberes, como inconformidade diante das certezas, é um esforço de desfamiliarização, de desnaturalização do que nos é apresentado como óbvio ou necessário. É por isso que muitas vezes ao pensarmos passamos a estranhar um pouco mais o mundo, os outros e a nós mesmos. E esse estranhamento talvez nos mostre que algo antigo que nos fazia ser quem éramos perde seu sentido. Quando pensamos nos lançamos junto com o nosso pensamento. Se há movimento e mudança no pensar, há transformação do que somos, há experiência.

O ensino da filosofia:

\section{Método e experiência}

A experiência como professora de filosofia é também constituída por diferentes retratos do ensino. Esses retratos são sustentados por saberes, por relações de poder e promovem distintos processos de subjetivação. Discutiremos a seguir duas imagens do ensino de filosofia e o que nelas pode vir a dificultar ou promover o filosofar como experiência.

Um primeiro retrato mostra o ensino da filosofia como a atividade de passar ou transmitir saberes do cânone filosófico para que os estudantes os dominem e sejam capazes de reproduzi-los. A lógica que move essa prática é a do reconhecimento $e$ da legitimação do que já foi pensado e, neste contexto, o professor faz muitas vezes da história da filosofia não uma inspiração ou um espaço de interlocução, mas justamente aquilo que dificulta o pensamento. Pouco ou nenhum espaço é intencionalmente gerado para a irrupção do pensamento dos estudantes ou do(a) próprio(a) professor(a). O que não quer dizer, porém, que, apesar de ser inexistente o convite ao pensar ou mínima a abertura ao novo, o filosofar não irrompa contrariando expectativas. A intencionalidade de quem organiza e oferece uma aula não garante o pensar ou a aprendizagem, não controla os acontecimentos. Por outro lado, o fato de não sabermos quando ou como o pensamento emergirá não diminui a tarefa de cuidar do que pode vir a promovêlo... e o que o promove talvez tenha a ver com a atenção que damos ao que nos passa, com os gestos de inquietude, a intimidade com as questões, a curiosidade $e$ a inconformidade frente ao mundo.

Um segundo retrato do ensino da filosofia centra-se no objetivo de fazer o aluno pensar. Ao contrário da primeira forma de ensino cuja ênfase recai sobre o conteúdo a ser dominado ou 'o que' da educação, privilegia-se agora o método ou o 'como' do ensino filosófico. Procura-se fazer com que o estudante discuta, argumente, ofereça exemplos e razões, estabeleça relações, identifique contradições, preveja conseqüências, conteste, conceitualize, mostre sua originalidade sobre o que se conversa no grupo. Acredita-se que uma vez desenvolvidas certas habilidades de raciocínio ou seguidos determinados passos no 
caminho do intelecto, chegar-se-á ao pensamento. Ou talvez este modo de ensino veja no exercício dessas habilidades ou na atualização desta metodologia a própria prática do pensar. Seja o filosofar fim ou meio, predomina para esta imagem do ensino a crença no método, em um caminho pré-estabelecido, conhecido e que se ensina a trilhar.

Algumas questões me preocupam nesta forma de conceber a educação filosófica. Uma delas diz respeito à posição que muitos professores passam a ocupar na relação com seus estudantes e com a própria filosofia. Reconheço que um jogo interativo desta natureza muitas vezes gera novas configurações de poder e que talvez contribua para desestabilizar certezas, o que faz dele algo imensamente mais interessante do que o ensino monológico e conteudístico tradicional. Por outro lado, temo que muitos professores se transformem em metodólogos, em especialistas no gerenciamento de regras, na formulação de perguntas $e$ distribuição de participações, técnicos do questionamento, jogadores tarimbados em um jogo cujo sentido se esvazia em sua forma. Tanto esforço para fazer pensar, tanta atenção destinada ao como se faz pensar, pode, inversamente do que se pretende, distanciar professores de seu próprio pensamento. Joga-se assim para que o outro aprenda a jogar, mas aquele que assim joga muitas vezes não se joga, mantém-se preso às regras do jogo.

Suspeito que pensar seja algo muito menos regrado, muito menos previsível. Talvez não haja passos predeterminados que nos levem ao pensar. Talvez não haja caminhos para o pensar, mas seja ele mesmo o que nos toma de assalto e nos força a sair de nossa rota, a perder a bússola, a nos perder. E, perdendo-nos, encontramo-nos com o novo, com o que é outro para nós e nos faz outro. $\mathrm{O}$ pensamento que nos tira o chão é uma experiência, um acontecimento. Aquilo que não se submete à intenção ou vontade do sujeito, mas o arrebata e o transforma.

Neste sentido, pensar é também algo bastante arriscado e perigoso. Não é possível prever o que dele resultará, o que nos tornaremos. E por isso é tão difícil pensar na educação, dentro de instituições programadas para produzir um certo tipo de ser humano, um certo tipo de sociedade. Em geral, não estamos dispostos a nos desfazer de nossas certezas e a nos deixar afetar pelo desconhecido, pelo que nos fará tomar formas não previsíveis. E talvez estejamos menos dispostos ainda a permitir que os outros, e principalmente as crianças, vivam essa experiência.

Diante dos perigos e riscos do pensar, para que ele irrompa mais facilmente, talvez precisemos nos nutrir de uma espécie de coragem e também de fragilidade. Embora não possamos garantir a ocorrência do pensamento, talvez possamos cultivar a força para nos mantermos abertos a ele e ao que nele há sempre de desconhecido, a coragem para suspeitar de nossas próprias certezas. E talvez possamos cultivar também a fragilidade para nos deixar abater, a sensibilidade para sermos por ele afetados. Um professor que se pretende amigo do pensar seria, neste sentido, alguém menos seguro de seus saberes, mais próximo de suas próprias inquietações, com um pouco mais de coragem para enfrentá-las e mais sensibilidade para se deixar transformar. 
Gênero e filosofia:

Os bastidores do pensamento

"Não me pergunte quem sou

e não me diga para permanecer o mesmo"

Michel Foucault, 1987, p. 20

Uma última reflexão, que costuma ser mais silenciosa no âmbito da academia e principalmente nos corredores da filosofia, diz respeito a questões de gênero. Em um mundo onde o corpo e a sexualidade são fortes traços identificatórios, definindo modos de pensar, maneiras de agir e produções de si, acredito ser de imensa relevância uma reflexão deste tipo. O exercício de pensar a experiência como mulher talvez nos ajude a identificar o que nos é imposto como natural ou necessário, impedindo-nos de ter relações mais interessantes com o mundo e com o nosso próprio pensamento. E começo já esclarecendo dois pontos. 1. Não tratarei aqui de opor o feminino ao masculino, de incitar ressentimentos, valorizar vitimizações, reforçando o jogo identitário e a ridícula "guerra dos sexos". Falo enquanto mulher porque me atribuíram este gênero, porque fui e sou constituída socialmente pelo que me dizem ser próprio do feminino, porque só encarando de frente o que marca esta minha experiência poderei modificá-la. Imagino que também haja inúmeras problematizações a serem feitas sobre a experiência de ser homem. Se o pensar tem a ver com o que nos afeta, cabe principalmente aqueles que vivem esta experiência problematizá-la. 2. Se falo enquanto mulher, explico, para que não haja dúvidas, que esse lugar não representa uma essência, um fato óbvio ou natural, mas a materialização de um sujeito generizado, um feixe de experiências atravessado por saberes, poderes, supostas verdades, valores, normas, limites e possibilidades. Não refletirei sobre este lugar (o do feminino) para dizer que não estamos sendo nosso verdadeiro eu e que por isso devemos pensar e agir de tal e tal forma para vivermos de fato o que significa ser mulher. Não há um verdadeiro eu a ser descoberto ou alcançado, mas diferentes 'eus' a serem criados. Eu sequer gostaria de precisar falar usando nomes tão carregados de representações e prescrições, conceitos como 'mulher' ou 'homem'. Se falo sobre a experiência como mulher, é porque sou movida pela crença de que a problematização desta mesma experiência talvez gere espaço para novas formas de pensar e ser, para novos jeitos de viver que, quem sabe, possam vir a prescindir até mesmo de um gênero.

A bipolarização do mundo social através do gênero figura entre outras partições binárias clássicas, tais como natureza/sociedade, corpo/mente, emoção/razão e privado/público. Historicamente, a experiência feminina tem se constituído em maior associação à natureza, ao corpo, à emoção e ao espaço privado.

Considerando a força dessa associação, não é estranho constatar que as mulheres tenham sido sistematicamente distanciadas do exercício público do pensamento $e$, portanto, da própria filosofia. A suposta verdade sobre o que significa ser mulher tem como efeito de poder a nossa reclusão, a nossa pouca participação na transformação dos saberes e normas que afetam a nossa própria vida $e$ a da sociedade. 
No âmbito da filosofia, o cânone legitimado institucionalmente excluiu - e nós também seguimos excluindo - as pensadoras de nossos estudos. Safo, Aspásia, Hildegarda de Bigen, Cristina de Pizan, Olímpia de Gouges, Rosa Luxemburgo, Edith Stein, Hannah Arendt, Simone de Beauvoir, entre tantas outras, contrariaram pretensões de silenciamento e mostraram a força de seu pensar. Conhecê-las talvez nos permita encontrar não modelos a reproduzir, mas interessantes exemplos de vidas filosóficas, interlocutoras que inspiram e potencializam nosso pensamento. Por serem essas filósofas tão pouco comentadas, muitos acreditam não haverem mulheres na história da filosofia, além de não existirem pensadoras na atualidade. A mulher, por ser regida por seus hormônios, por sua intuição e sensibilidade, quando filósofa ou vive uma contradição ou não é assim tão feminina. Possui traços masculinos. Não é uma verdadeira mulher. Muitos pensariam que a mulher filósofa não é bem filósofa, mas, quando muito, professora de filosofia. E assim nos encontraríamos com outra problemática bipartição que não discutiremos nesta ocasião: a que divide os que se dedicam à filosofia entre filósofos (pensadores, mas mais freqüentemente comentadores de pensadores) e professores de filosofia (repetidores ou comentadores dos comentadores de pensadores). Ser professora de filosofia não seria algo assim tão surpreendente para as mulheres, visto que ensinar seria reproduzir e não pensar, e que a sala de aula é um lugar quase privado, um lugar onde se cuida do outro, é quase um lar.

Além de nos incomodarmos com o espaço simbólico e concreto construído para as professoras de filosofia, talvez valha a pena também nos inquietarmos um pouco mais com a posição ocupada pelas estudantes. Fui professora de um curso de pedagogia e atuei por algum tempo em um projeto de extensão com alunos da universidade e professores da rede pública. Nos dois contextos, embora o número de mulheres fosse sempre muito superior, a participação masculina muitas vezes ocorria com maior freqüência e com mais desenvoltura. Os homens costumavam fazer uso da palavra por mais tempo e de forma mais confiante. Quando eu chamava a atenção da turma para este fato, não era raro ouvir que eles diziam o que elas estavam pensando, ou que alguns homens sentiam-se mais à vontade para falar porque era próprio da personalidade deles. Debatíamos então sobre a possibilidade de que alguém diga exatamente o que outro pensa, se há pensamentos idênticos, se há correspondência entre pensar e dizer. Explorávamos as possíveis conseqüências de uma omissão da fala, de deixar que os outros a exerçam por mim. Discutíamos também se a personalidade era natural e fixa ou se era contigente, constituída socialmente. Se o nosso modo de ser é algo que aprendemos, então vale a pena refletir sobre o que atua inibindo as falas $e$ provavelmente o pensamento de muitas estudantes, vale a pena problematizar inclusive o que julgamos ser próprio, subjetivo, íntimo, privado ou pessoal, identificar as marcas sociais que, sem percebermos, nos prendem a uma política de gênero que polariza, hierarquiza e fixa identidades de forma assimétrica.

Sentimentos íntimos como o medo do público, a vergonha, a estima baixa, a dependência da aceitação do outro, entre outros, são produzidos a todo momento nas relações, constituindo a experiência feminina e nos fazendo descrentes de nosso próprio pensamento. Em nossa autodomesticação cotidiana, fabricamo-nos segundo uma imagem que dificulta que pensemos e ajamos de outras formas, que 
sejamos outras. Se pensar é uma atividade perigosa, se significa colocar em risco certezas, códigos de conduta e a nossa relação com o que vínhamos sendo, talvez valha muito a pena buscar forças para pensarmos, para transformarmos o que em nossa experiência nos enclausura em um modo de ser docilizado. Nenhum príncipe virá ao nosso socorro. Sair da masmorra é uma tarefa de cada uma e de todas.

Criação e filosofia:

a vida filosófica como obra de arte

"Dar estilo a seu caráter - eis uma grande e rara arte!

Aquele que a exerce apreende tudo

o que a natureza lhe oferece de forças e fraquezas,

e sabe em seguida adaptá-las a um plano artístico, até que cada coisa apareça em sua arte e sua razão" Friedrich Nietzsche, 1978/1881, p. 135

Percorridas algumas reflexões sobre a experiência do filosofar, sobre como, muitas vezes, a forma como nos relacionamos com os saberes filosóficos, com sua prática de ensino $e$ a noção de gênero dificultam o filosofar como experiência, resta-nos apontar agora como toda esta discussão se associa intensamente à arte, tema que aparece em conjunção à filosofia e à educação neste colóquio.

Vimos como o pensamento enquanto experiência pouco tem a ver com o reconhecimento e a legitimação do que já sabemos, com o trilhar de passos préestabelecidos, com a solidificação de nossas formas de ser. O pensar relaciona-se sim com o diferente e com o imprevisível, com o desconhecido. Sua irrupção é um acontecimento que inaugura o novo, o novo no pensamento, o novo na vida. Através do pensar nos tornamos outro, outra. A relação entre o pensar $e$ a fluidez das formas de vida já era indicada por Nietzsche (1978/1881, p. 109), que dizia que "é preciso saber, de tempo em tempo, perder-se - e depois reencontrar-se: pressuposto que se seja um pensador", pois para pensar "é prejudicial estar sempre ligado a uma pessoa". Estar ancorado em saberes sólidos e formas de ser sedimentadas impede o movimento do pensar, que, além de desconstrutivo, é também um movimento do criar.

A forte conexão do pensamento com a criação e o novo vem fazendo, a partir de Nietzsche e outros contemporâneos, com que o relacionemos à arte. A arte seria a forma mais apropriada para aludir ao fluxo vital potencializado pelo pensamento, para se referir à criação como experiência, para celebrar a atividade filosófica que instaura novas formas de pensar e ser. O pensamento contribui, nesta perspectiva, para a 'arte de viver', para a permanente construção e destruição de formas, para o exercício de imprimir um estilo próprio aos atos e idéias.

A vida filosófica como obra de arte se constitui através do cultivo de regras facultativas que são ao mesmo tempo estéticas e éticas. Não se trata mais de delinear jeitos de ser pautados por formas determinadas, como os que ocorrem em 
relações de reverência ao saber, ou por regras coercitivas, como os que se paralisam frente ao poder, mas da criação de modos de vida, da invenção de possibilidades de vida, cujas regras se dão em função do modo de existência que implicam. Sua dimensão ética diferencia-se da moral porque, enquanto a moral se apresenta como um conjunto de regras que coagem, que consistem em julgar ações e intenções referindo-as a valores transcendentes (ao certo e ao errado), a ética diz respeito a um conjunto de regras facultativas que avaliam o que fazemos, o que dizemos e pensamos considerando não as imposições ou um código fixo estabelecido, mas o tipo de vida que fazem nascer (Foucault, 1996, p. 94-97; Deleuze, 1992, p. 123-126).

Viver filosoficamente, transformando nossa existência em algo intenso e belo, é um enorme desafio. E este desafio parece-me ainda mais marcante e amplo quando grande parte de nossa experiência se constitui no terreno da educação. Como gerar espaço para o pensamento e novos modos de vida em um contexto onde impera a reprodução de respostas para as perguntas que sequer formulamos? Como pensar quando estamos submetidos a verdades estéreis e à arrogância dos que sabem? Como estar aberta à novidade no emaranhado de práticas que tentam concretizar, a todo momento e a qualquer custo, seu ideal de ser humano e sociedade? E como deixar, sem impor caminhos ou pontos de chegada, que aqueles com os quais me encontro percorram o seu próprio pensamento, potencializando suas vidas, transformando-as em algo pleno e admirável?

\section{Bibliografia}

ARTAUD, Antonin. Acabar com as obras primas. Escritos de Antonin Artaud. Porto Alegre: L\&PM Editores, 1983.

DELEUZE, Gilles. Diferença e repetição. Rio de Janeiro: Edições Graal, 1988. . Conversações. São Paulo: Editora 34, 1992.

DELEUZE, Gilles, PARNET, Claire. Diálogos. São Paulo: Escuta, 1998.

FOUCAULT, Michel. História da Sexualidade 2 - O uso dos prazeres. Rio de Janeiro: Graal, 1984.

. A arqueologia do saber. Rio de Janeiro: Forense Universitária, 1986.

. Microfísica do poder. Rio de Janeiro: Edições Graal, 1988.

. Dits et écrits. Paris: Gallimard, vol. IV, 1994.

O sujeito e o poder. In: Rabinow, P; Dreyfus, H. Michel Foucault, uma trajetória filosófica. Rio de Janeiro, Forense Universitária, 1995. 
Hermenéutica del sujeto. La Plata: Editorial Altamira, 1996.

KOHAN, Walter. Infância. Entre educação e filosofia. Belo Horizonte: Autêntica, 2003.

NASCIMENTO, Wanderson F. Notas sobre o pensar e o fazer: Um diálogo com a filosofia na formação de professores, 2004 (Prelo).

NIETZSCHE, Friedrich. A gaia ciência. Coleção Os Pensadores. São Paulo: Abril Cultural, 1978/1881.

(1) Doutoranda em Educação da Universidade Estadual do Rio de Janeiro (UERJ). 